\title{
5-Fluorouracil induced severe febrile neutropenia and death
}

\author{
Vinodkumar Mugada ${ }^{1}$, Haribabu Ramineni ${ }^{2}$, Dharmareddy Padala ${ }^{1}$ \\ 'Department of Pharmacy Practice,Aditya Pharmacy College, Surampalem, A.P, INDIA. \\ 2Department of Clinical Pharmacy, Chebrolu Hanumaiah Institute of Pharmaceutical Sciences, Guntur, A.P., INDIA.
}

\begin{abstract}
5-Fluorouracil (5-FU) induced severe febrile neutropenia is a serious threat which, if unnoticed may lead to death. We present here a case of 46 years old female patient who suffered severe febrile neutropenia and finally death due to 5-FU. Naranjo's causality assessment revealed that 5-Fluorouracil was the probable cause of severe febrile neutropenia. 5-Fluorouracil induced hematological toxicities vary between individuals. Of them, severe febrile neutropenia is a serious threat, which increases the vulnerability of patient to bacterial infections. Patients must be made aware of the side effects of chemotherapy through proper medication counselling and clear take home information. It helps them to consult the physician at the right time so that the side effects can be managed in time.
\end{abstract}

Key words: 5-FU, chemotherapy, severe febrile neutropenia, Naranjo, hematological toxicity.

Correspondence :

Vinodkumar Mugada, M.Pharm (Ph.D),

Assistant Professor, Department of Pharmacy Practice, Aditya Pharmacy College, ADB road, Surampalem Kakinada, East Godavari District A.P, INDIA.

Contact no.: 7095197222

E-mail: mugadavinodkumar18@gmail.com

DOI: $10.5530 / j y p .2017 .9 .26$

\section{INTRODUCTION}

5-FU as a single agent therapy or in combination with other anticancer drugs, used in the treatment of various human malignancies, including gastrointestinal cancer, breast cancer, head and neck cancer. 5-FU is a highly toxic drug with a narrow therapeutic index. Severe haematological toxicity, gastrointestinal complications may result from the use of 5-FU despite the scrupulous selection of patients and careful adjustment of dosage. It has wide inter-patient variability in toxicity. The toxicity of 5 -FU is rather predictable based on dose, schedule and route of administration. ${ }^{1}$

Febrile Neutropenia (FN) possess a serious threat to the patients who are on cytotoxic chemotherapy, predisposing them to the risk of infections. The Infections Diseases Society of America (IDSA) has published guidelines for the treatment of neutropenic patients with cancer who become febrile. For the majority of patients with FN, hospitalization with intravenous antibiotics remains standard of care. ${ }^{2}$

To the author's knowledge, very few case reports have been reported on 5-FU induced severe febrile neutropenia and death in patient suffering from throat cancer. ${ }^{5}$

\section{CASE HISTORY}

A 46 year old female patient presented to oncology department with chief complaints of throat pain, difficulty breathing, enlarged lymph nodes and dysphagia. The biopsy report revealed that she was suffering from throat cancer. Her past medical and medication history was not significant. She was a non-smoker and non-alcoholic. Her complete blood cell count was normal. 5-Fluorouracil (5-FU) as a single agent therapy was advised for her. 5-FU, $1000 \mathrm{mg}$ was administered as an intravenous infusion successively for 3 days to complete first cycle of chemotherapy. She did not experience any side effects during the therapy. She was discharged and asked for review after 15 days.

After 15 days she was again admitted in oncology ward with complaints of severe fever, breathlessness and blood vomitings. Complete Blood
Cell count was advised immediately to rule out severity of haematological toxicity. Her lab investigations revealed abnormal readings of Haemoglobin $\left(7.8 \mathrm{gm} / \mathrm{dl}\right.$ ), Neutrophils (ANC 700 cells $/ \mathrm{mm}^{3}$ ), and Platelets (0.83 lakhs). She was treated aggressively with Metronidazole $400 \mathrm{mg}$, a combination of cefoperazone and sulbactam $1.5 \mathrm{gm}$ intravenously and Pegylated filgrastim $6 \mathrm{mg}$ subcutaneously. Unfortunately, patient died during the process of rescue. Upon enquiring the patient care givers it was revealed that the patient suffered from severe fever during their stay at home. Paracetamol $500 \mathrm{mg}$ was used to take over fever. They failed to intimate the severity of fever to the physician and opted self medication. The exact reason for her death was remained unknown.

Naranjo's Causality assessment revealed that 5-FU was the "probable" cause (overall score 8) of the severe febrile neutropenia. Hartwig's Severity scale revealed that it is Level 7 severity that directly or indirectly lead to the death of the patient. It is "definitely preventable" reaction according to Schumock and Thornton Preventability scale.

\section{DISCUSSION}

5-FU has wide inter-patient variability in toxicity. 5-FU induced small bowel toxicity is a potentially severe toxicity that may occur in patients with colon carcinoma or other malignancies who are receiving 5-FU based therapy. ${ }^{3} 5$-FU based combination regimens also associated with severe gastrointestinal toxicity and high mortality rates. ${ }^{4}$ Some studies reported that partial or complete deficiency of DihydroPyrimidine Dehydrogenase (DPD) is associated with increased risk of grade IV neutropenia after administration of 5 -FU. ${ }^{5}$ The association between deficiency in DPD and febrile neutropenia in this case was not ruled out because there is no opportunity to identify mutations underlying DPD deficiency.

Cytotoxic chemotherapy suppresses both cancer cells and rapidly dividing healthy cells like skin, bone marrow, mucous membranes etc. Of them, chemotherapy induced haematological toxicity have a concern since it affects haemoglobin levels, blood clotting mechanisms, host defense mechanisms. Reduced levels of Neutrophils predispose the individual to 
risk of infections. According to Common Toxicity Criteria for Adverse Events of National Cancer Institute, Febrile Neutropenia was divided into 5 Grades. ${ }^{6}$ In this case, the patient suffered from grade 3 febrile neutropenia i.e. $\mathrm{ANC}<1000 / \mathrm{mm}^{3}$ with a single temperature of $>38.3$ degrees C (101 degrees F) or a sustained temperature of $>=38$ degrees $C$ (100.4 degrees F) for more than one hour. Grade 3 refers adverse event that is severe or medically significant, but not immediately life threatening; hospitalization or prolongation of hospitalization is required; disabling; limited self care activities of daily living. Naranjo's Causality Assessment revealed that 5-FU was the "probable" cause of febrile neutropenia with level 7 severity which directly or indirectly caused the death of the patient.

The patient should be treated with empirical antibiotics until the blood count results are known. However, there are data suggesting that broad spectrum antibiotic monotherapy can be effective, particularly in low risk patients. Here the patient was treated with a combination of Cefoperazone and Sulbactam which has a broad spectrum activity against various bacterial infections. Metronidazole is one of the main drugs which often used for treatment of anaerobic infections. The patient was treated Pegylated Filgrastim. Treatment with Granulocyte-Colony Stimulating factor (G-CSF) is advocated if the patient is clinically septic and /or hypotensive, expected to have neutropenia of long duration (as with certain chemotherapeutic regimens for haematological diseases), or has organ dysfunction. ${ }^{7}$

The patient had suffered a severe fever during their stay at home. Inspite of intimating the same to the physician, they opted self medication to take over the fever. As a result of this, the chance of treating neutropenia was delayed, which worsened the condition of the patient further. The patient should be aware of of typical signs of febrile neutropenia which includes a temperature higher than $37.5^{\circ} \mathrm{C}$, flulike symptoms, mouth ulcers or a sore mouth that prevents eating. ${ }^{8}$ Patient education and sound written information will help the patient to be aware of the early symptoms of febrile neutropenia.

To conclude 5-FU induced febrile nuetropenia possess a threat to patient, which increases the risk of infection apart from increasing the chances of delay in treatment and also reduction in dose.The association between DPD deficiency and 5-FU induced severe febrile neutropenia was not ruled out due to lack of opportunities and the reason for the death of the patient was remained unclear. The patient should be made aware of the most common and severe haematological toxicities that may be experienced by them through patient education and easy to understand written information. They also should be warned about intimation of side effects which didn't subside after following the management strategies suggested by physician.

\section{ACKNOWLEDGEMENT}

We express our sincere gratitude to Dr. P. Prasanth, Medical Officer, and Department of Radiotherapy for his valuable timely suggestions.

\section{CONFLICTS OF INTEREST}

None declared.

\section{ABBREVIATIONS USED}

5-FU: 5-Fluorouracil; FN: Febrile Neutropenia; IDSA: Infectious Diseases Society of America; DPD: DIhydro Pyrimidine Dehydrogenase.

\section{REFERENCES}

1. Germ JL. Fluorinated pyrimidines. In: Chatsner BA, Collins JM, editors. Cancer chemotherapy principles and practice. Philadelphia: J B Lippincott Co. 1990:197200.

2. Hughes WT, Armstrong D, Bodey GP, et al. Guidelines for the use of antimicrobial agents in neutropenic patients with cancer. Clin Infect Dis. 2002;34(6):73051. http://dx.doi.org/10.1086/339215; PMid:11850858.

3. Farid F, Ilan GR, Nancy K. Eileen O'Reilly, David Klimstra, David P. Kelsen. 5-Fluorouracil-Induced Small Bowel Toxicity in Patients with Colorectal Carcinoma. Cancer. 1999;86(7):1129-34. http://dx.doi.org/10.1002/(SICI)10970142(19991001)86:7<1129::AID-CNCR5>3.0.CO;2-4.

4. Thierry D, Richard MG, Daniel J. Sargent, Roscoe F. Morton et al. Mortality Associated with Daily Bolus 5-Fluorouracil/Leucovorin Administered in Combination with Either Irinotecan or Oxaliplatin. Results from Intergroup Trial N9741. Cancer. 2004;101(10): 2170-6. http://dx.doi.org/10.1002/ cncr.20594; PMid:15470715.

5. Andre B.P.Van Kuilenburg, Rutger Meinsma, Lida Zoetekouw, and Albert H. Van Gennip. Increased Risk of Grade IV Neutropenia after Administration of 5-Fluorouracil Due To A Dihydropyrimidine Dehydrogenased Efficiency: High Prevalence of the IVS14+1G>A Mutation. Int. J. Cancer. 2002;101:253-8. http:// dx.doi.org/10.1002/ijc.10599; PMid:12209976.

6. Common Terminology Criteria for Adverse Events version 4.0,2009. [Last cited on 2016 June 21]. Available from URL: http://evs.nci.nih.gov/ftp1/CTCAE/CTCAE_4.03_2010-06-14_QuickReference_8.5×11. pdf.

7. North Wales Cancer Network Guidelines for the Use of Colony Stimulating Factor (G-CSF) in Adult Patients with Solid Tumours. NWCN: St Asaph; 2007.

8. Malik I, Hussain M, Yousuf $\mathrm{H}$. Clinical characteristics and therapeutic outcome of patients with febrile neutropenia who present in shock: need for better strategies. J Infect. 2001;42(2):120-5. http://dx.doi.org/10.1053/jinf.2001.0798; PMid:11531318. 